\title{
Carcaça e componentes corporais de cordeiros lactentes em pastejo de azevém suplementados com leguminosa ou concentrado
}

[Carcass and body components of suckling lambs grazing ryegrass and supplemented with legume or concentrate]

\author{
A.C.R.S. Pellegrin ${ }^{1}$, C.C. Pires $^{2}$, R.O. Mello ${ }^{2}$, R.S. Venturini ${ }^{1}$, R.R. Simões ${ }^{1}$, G.M.C. Bernardes ${ }^{1}$, \\ L. Griebler ${ }^{3}$, J.F. Lopes ${ }^{4}$, M.F. Frasson ${ }^{1}$, A.B. Moro ${ }^{1}$, A.M. Menegon ${ }^{5}$, V.L. Mello \\ ${ }^{1}$ Alunos de pós-graduação - Universidade Federal de Santa Maria - Santa Maria, RS \\ ${ }^{2}$ Universidade Federal de Santa Maria - Santa Maria, RS \\ ${ }^{3}$ Universidade do Oeste de Santa Catarina - Xanxerê, SC \\ ${ }^{4}$ Aluna de pós-graduação - Universidade Federal do Rio Grande do Sul - Porto Alegre, RS \\ ${ }^{5}$ Alunos de graduação - Universidade Federal de Santa Maria - Santa Maria, RS
}

\begin{abstract}
RESUMO
O objetivo desta pesquisa foi avaliar o efeito da suplementação privativa, com concentrado ou leguminosa, sobre as características da carcaça e dos componentes corporais de cordeiros lactentes mantidos em pastejo de azevém. Foram utilizados 27 cordeiros lactentes, distribuídos nos tratamentos que corresponderam aos sistemas de alimentação: cordeiros lactentes mantidos em pasto de azevém, cordeiros lactentes mantidos em pasto de azevém e suplementados com concentrado em comedouro privativo (creep feeding) e cordeiros lactentes mantidos em pasto de azevém e suplementados com leguminosa no pasto privativo (creep grazing). O concentrado era composto por milho, farelo de soja e calcário calcítico, e a leguminosa utilizada foi o trevo-branco. O delineamento experimental foi o inteiramente ao acaso. Os resultados foram submetidos à análise de variância, e as médias comparadas pelo teste de Tukey a 5\% de significância. $\mathrm{O}$ conteúdo do trato gastrintestinal juntamente com bile e urina e a proporção de esôfago foram maiores $(\mathrm{P}<0,05)$ nos cordeiros mantidos em pasto de azevém. As proporções de fígado e intestino grosso foram maiores $(\mathrm{P}<0,05)$ nos cordeiros suplementados com concentrado. Os sistemas alimentares testados produzem carcaças com características semelhantes. A suplementação, com leguminosa ou concentrado, altera os componentes corporais de cordeiros lactentes mantidos em azevém.
\end{abstract}

Palavras-chave: fígado, intestino, ovinos, suplemento, trevo-branco

\begin{abstract}
This research objective was to evaluate the effect of private supplementation with concentrated or legumes, on the carcass characteristics and body components from suckling lambs kept on ryegrass

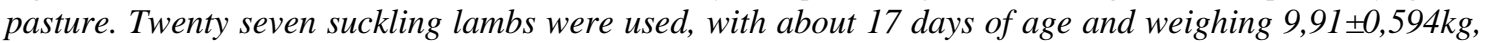
which were distributed in the treatments that corresponded to feeding systems: suckling lambs kept on ryegrass pasture, suckling lambs kept on ryegrass pasture and supplemented with concentrated in private feeder (creep feeding) and suckling lambs kept on ryegrass pasture and supplemented with legume in the private pasture (creep grazing). The concentrate supplement was composed by corn, soybean meal and limestone, and was supplied ad libitum. The supplementary pasture was white clover legume. The experimental design was completely randomized, where the results were submitted to analysis of variance and means compared by Tukey test at 5\% of significance level. The gastrointestinal+bile+urine content and the proportion of esophagus were higher $(P<0,05)$ in lambs kept on ryegrass. The liver and large intestine proportions were higher $(P<0,05)$ in lambs supplemented with concentrate. The tested alimentary systems produce carcasses with similar characteristics. The supplementation with legume or concentrate cause changes in body components of suckling lambs grazing ryegrass.
\end{abstract}

Keywords: intestine, liver, sheep, supplement, white clover

Recebido em 3 de fevereiro de 2017

Aceito em 5 de agosto de 2017

E-mail: carolsanquetta@hotmail.com 


\section{INTRODUÇÃO}

O aumento na procura por carne ovina, nos últimos anos, fez com que fosse necessário o melhoramento das técnicas de produção, para que, cada vez mais, o produto oferecido seja de maior qualidade. Com isso, o abate de animais jovens ganhou força para atender um mercado cada vez mais exigente (Hashimoto et al., 2009).

Para a terminação precoce, uma das maneiras mais econômicas é a terminação dos cordeiros ainda lactentes e mantidos a pasto (Barros et al., 2009). Contudo, a suplementação privativa aos cordeiros lactentes, seja por meio de concentrado, seja por meio de pastagens de alta qualidade, vem se fortalecendo e despertando o interesse como métodos precoces de terminação de cordeiros.

Nos sistemas de produção com oferta de pasto privativo aos cordeiros lactentes, são normalmente utilizadas forragens de alta qualidade nutricional, como as leguminosas, que podem servir como banco de proteína aos animais (Ribeiro et al., 2013). Esse sistema constitui uma real opção para terminação de cordeiros precoces de forma sustentável e econômica, quando comparado com a suplementação concentrada, já que não há a necessidade da compra de grãos.

Em sistemas de terminação, a carcaça é o componente mais importante gerado pelo animal, pois nela está contida a parte rentável do produto final; nos sistemas de produção de carne, o conhecimento das características qualiquantitativas da carcaça é relevante, pois essas características estão diretamente relacionadas ao produto de origem animal gerado (Souza et al., 2009).

Os principais fatores que interferem na qualidade das carcaças, assim como nos componentes que não a constituem, são genótipo, estado sanitário, idade, sexo e alimentação. O sistema alimentar utilizado na terminação de cordeiros pode alterar o rendimento de carcaça e influi sobre sua qualidade, seja atuando sobre o crescimento do animal e o estado de engorduramento, seja condicionando as características da carne e da gordura (Costa et al., 2009).
A presente pesquisa foi realizada com o objetivo de avaliar o efeito da suplementação privativa, com concentrado ou leguminosa, sobre as características da carcaça e dos componentes corporais de cordeiros lactentes mantidos em pastejo de azevém.

\section{MATERIAL E MÉTODOS}

Esta pesquisa foi realizada no Laboratório de Ovinocultura do Departamento de Zootecnia da Universidade Federal de Santa Maria, Santa Maria - RS e foi aprovada pela Comissão de Ética no Uso de Animais da mesma instituição $\left(n^{\circ} 058 / 2013\right)$.

Foram utilizados 27 cordeiros lactentes de partos simples, sendo esses 21 machos não castrados e seis fêmeas, oriundos do cruzamento entre as raças Texel $x$ Ile de France, tendo aproximadamente 17 dias de idade e pesando $9,91 \pm 0,594 \mathrm{~kg}$. Os animais foram igualmente distribuídos em três tratamentos, que corresponderam aos sistemas de terminação: cordeiros lactentes mantidos em pasto de azevém, cordeiros lactentes mantidos em pasto de azevém e suplementados com concentrado em comedouro privativo (creep feeding) e cordeiros lactentes mantidos em pasto de azevém e suplementados com leguminosa no pasto privativo (creep grazing).

O experimento ocupou uma área de 2,3ha, que foi subdividida em nove piquetes, sendo três para cada tratamento, contendo três animais testes em cada, totalizando nove animais testes por tratamento. Os animais foram transferidos para a pastagem uma semana antes do início do período de coleta de dados para adaptação ao ambiente e às dietas. Em cada piquete, havia suplementação mineral e água à vontade para ovelhas $\mathrm{e}$ cordeiros.

O suplemento mineral utilizado era específico para ovinos (Suprasal Ovinos ${ }^{\circledR}$, sal mineral, Supra, Brasil), sendo composto de: $145 \mathrm{~g} / \mathrm{kg}$ de cálcio, $135 \mathrm{~g} / \mathrm{kg}$ de sódio, $85 \mathrm{~g} / \mathrm{kg}$ de fósforo, $4000 \mathrm{mg} / \mathrm{kg}$ de zinco, $1400 \mathrm{mg} / \mathrm{kg}$ de manganês, $850 \mathrm{mg} / \mathrm{kg}$ de flúor, $150 \mathrm{mg} / \mathrm{kg}$ de molibdênio, $80 \mathrm{mg} / \mathrm{kg}$ de iodo, $60 \mathrm{mg} / \mathrm{mg}$ de cobalto, $25 \mathrm{mg} / \mathrm{kg}$ de selênio, $18 \mathrm{mg} / \mathrm{kg}$ de enxofre e $10 \mathrm{mg} / \mathrm{kg}$ de magnésio. 
Os animais foram mantidos em pasto de azevém anual (Lolium multiflorum Lam.), em sistema de lotação contínua com carga animal variável (Mott e Lucas, 1952), sendo os animais testes mantidos continuamente na área experimental, enquanto o número de animais reguladores variou para ajuste da carga animal, o qual foi realizado a cada 21 dias, visando manter a massa de forragem em $1.200 \mathrm{~kg}$ de MS/ha.

A leguminosa trevo-branco (Trifolium repens) compôs o pasto suplementar. A área da pastagem era cercada, permitindo acesso apenas aos cordeiros por uma pequena entrada. A pastagem foi implantada, um ano antes de sua utilização, tendo 0,2 ha cada piquete em que este tratamento estava presente, totalizando cerca de 0,6 ha de área total de trevo. As características da pastagem de trevo-branco foram: $15,11 \mathrm{~cm}$ de altura, $3.182,67 \mathrm{~kg} \mathrm{MS} / \mathrm{ha}$ de massa de forragem e $77,03 \mathrm{~kg} \mathrm{MS} / \mathrm{ha} / \mathrm{dia}$ de taxa de acúmulo. A pastagem foi composta por $19,49 \%$ de folha, $26,57 \%$ de colmo, $17,01 \%$ de material morto e $13,56 \%$ de inflorescência, bem como por $23,37 \%$ de outras espécies.

A suplementação concentrada foi fornecida ad libitum no comedouro privativo, com suplemento concentrado composto por $80,67 \%$ de grão de milho moído, $18,83 \%$ de farelo de soja e $1,30 \%$ de calcário calcítico, contendo na matéria seca $18 \%$ de PB, 19,60\% de FDN, 2,40\% de FDA, $83,09 \%$ de NDT, $0,51 \%$ de cálcio e $0,29 \%$ de fósforo. A quantidade ofertada foi ajustada diariamente, de forma a manter as sobras em aproximadamente $10 \%$ do total oferecido. O consumo de concentrado suplementar no comedouro privativo estimado foi de $1,15 \%$ do peso corporal por animal.

Ao atingirem o peso corporal de $32 \mathrm{~kg}$ (peso de fazenda - PF), os animais foram submetidos a jejum prévio de sólidos por 14 horas e pesados novamente para a determinação do peso de abate (PA). Posteriormente, foram insensibilizados e, então, abatidos. As perdas pelo jejum (PPJ) foram obtidas por meio de cálculo correspondente à diferença entre o peso de fazenda e o peso ao abate e expressas em porcentagem de peso corporal (PC).

Durante o processo de abate, o sangue de cada animal foi recolhido em recipiente apropriado e pesado. Após esfola e evisceração, pesaram-se separadamente cada componente corporal (cabeça, língua, pulmão+traqueia, diafragma, timo, esôfago, rúmen, retículo, omaso, abomaso, intestino delgado, intestino grosso, fígado, vesícula biliar, pâncreas, baço, coração, rins, bexiga, gordura perirrenal, gordura do coração, gordura interna, aparelho reprodutor, patas, pele e sangue), e suas proporções foram calculadas em relação ao peso de corpo vazio.

O conteúdo gastrintestinal, a bile e a urina (TGBU) foram descartados para obtenção do peso corporal vazio (PCV): $\mathrm{PCV}=\mathrm{PA}-$ (conteúdo gastrintestinal + bile + urina), sendo este avaliado em $\mathrm{kg}$ e porcentagem. Posteriormente, realizou-se a pesagem da carcaça para obtenção do peso de carcaça quente (PCQ). Pela relação entre o PA e o PCQ, obteve-se o rendimento de carcaça quente $(\mathrm{RCQ}=(\mathrm{PCQ} / \mathrm{PA})$ $\times 100)$. Em seguida, as carcaças foram levadas à refrigeração em câmara frigorífica a $2^{\circ} \mathrm{C}$, por 24 horas.

Transcorrido o período de resfriamento, as carcaças foram novamente pesadas para obtenção do peso de carcaça fria (PCF), rendimento de carcaça fria $(\mathrm{RF}=(\mathrm{PCF} / \mathrm{PA}) \times$ $100)$ e da quebra ao resfriamento $(\mathrm{QR}=100$ $((\mathrm{PCF} / \mathrm{PCQ}) \times 100)$. Determinou-se, ainda, como características subjetivas, o estado de engorduramento da carcaça, que expressa a quantidade e a distribuição harmônica da gordura na carcaça $(1,0=$ excessivamente magra até $5,0=$ excessivamente gorda), e a conformação da caraça $(1=$ muito pobre a $5=$ excelente $)$, que indica o desenvolvimento das massas musculares (Osório et al., 1998).

Posteriormente, as carcaças foram seccionadas longitudinalmente ao meio, obtendo-se duas meias carcaças. $\mathrm{Na}$ metade esquerda, mensuraram-se o comprimento de carcaça (distância máxima entre o bordo anterior da sínfise ísquio-pubiana e o bordo anterior da primeira costela em seu ponto médio), o comprimento de perna (bordo anterior do osso do púbis e no ponto médio dos ossos da articulação do tarso), a largura de perna (distância entre os bordos interno e externo da porção superior da perna em sua parte mais larga), a profundidade de perna (máxima distância entre os bordos anterior e posterior da perna em sua porção superior) e a profundidade de peito (entre o dorso e o osso esterno, na região das cruzes em sua 
distância máxima), também segundo Osório et al. (1998). A compacidade da carcaça (CCar) foi determinada por meio do PCF, em função do comprimento da carcaça $(\mathrm{CC}), \quad(\mathrm{CCar}=$ $\mathrm{PCF} / \mathrm{CC})$, sendo expressa em $\mathrm{kg} / \mathrm{cm}$.

Após a exposição do músculo longissimus dorsi depois de um corte transversal na carcaça entre a $12^{\mathrm{a}}$ e a $13^{\mathrm{a}}$ costela, foi mensurada a espessura de gordura de cobertura (EG), em mm (milímetros), com o uso do paquímetro. No mesmo músculo, de forma subjetiva, foi determinada a gordura de marmoreio (gordura intramuscular), em uma escala de 1 a 5 , em que $1,0=$ inexistente e 5,0 = excessiva, e a textura $(1,0=$ muito grosseira e 5,0=muito fina) (Osório et al., 1998). A área de olho-de-lombo (AOL) foi obtida traçando-se o contorno do músculo em papel vegetal para posterior cálculo, sendo a área da figura determinada em mesa digitalizadora, com o auxílio de programa computacional.

Em seguida, procedeu-se à separação regional da meia carcaça direita em quatro cortes: pescoço, costela e pernil, de acordo com Osório et al. (1998), e a paleta, conforme Colomer-Rocher et al. (1988). Cada corte foi pesado individualmente e, posteriormente, suas proporções foram calculadas em relação ao peso da meia carcaça direita.

As paletas foram separadas, identificadas e congeladas em freezer para posterior determinação da composição tecidual delas. Depois de descongelada, cada paleta foi pesada e, em seguida, procedeu-se à separação física, com o auxílio de bisturi e pinça em: osso, músculo, gordura e outros tecidos (vasos, nervos, gânglios linfáticos, tendões, aponeuroses e fáscias), de acordo com Colomer-Rocher et al. (1988). Cada um dos componentes teciduais que compunham as paletas foi pesado, e sua proporção calculada em relação ao corte.

Os dois músculos longissimus dorsi foram retirados inteiros de cada meia carcaça e, então, pesados, obtendo-se, assim, o peso total de lombo, sendo cada porção dos músculos destinada a demais análises.

O delineamento experimental foi o inteiramente ao acaso. Os resultados foram submetidos à análise de variância, e as médias comparadas pelo teste Tukey a 5\% de significância. Os dados obtidos que não atenderam às premissas de normalidade foram transformados ou analisados por meio do teste não paramétrico de KruskalWallis. As análises foram realizadas utilizandose o programa estatístico SAS (2008).

\section{RESULTADOS E DISCUSSÃO}

Não houve efeito $(\mathrm{P}>0,05)$ dos sistemas de alimentação sobre o peso de fazenda, sendo isso esperado, já que tal peso foi preestabelecido $(32 \mathrm{~kg})$. Por outro lado, o conteúdo do TGBU, expressos tanto em $\mathrm{kg}$ como em porcentagem, foi alterado pela dieta $(\mathrm{P}<0,05)$ (Tab. 1), resultando em que os animais não suplementados apresentaram os maiores valores.

A menor digestibilidade do volumoso ingerido pelos animais e os maiores teores de FDN da dieta proporcionam elevação do peso e proporção de conteúdo gastrintestinal (Brochier e Carvalho, 2008). Resultados de Piazzetta et al. (2009) demonstram que a presença da leguminosa trevo-branco na dieta de cordeiros em sistemas de creep grazing, pelo maior teor de PB e, principalmente, menores teores de FDN, deve melhorar as condições de fermentação ruminal, aumentando a taxa de passagem do alimento no rúmen, o que justificaria o menor conteúdo TGBU encontrado nos animais desse sistema de terminação.

Foram observadas diferentes proporções de intestino grosso (Tab. 2), sendo o sistema de alimentação em que a leguminosa trevo-branco estava presente o que teve a menor proporção desse órgão, ao contrário do sistema com suplementação concentrada, que teve a maior proporção $(\mathrm{P}<0,05)$.

A maior digestibilidade da dieta e os menores teores de FDN fizeram com que houvesse um menor conteúdo de TGBU nesse tratamento, o que pode ter proporcionado esse menor desenvolvimento do intestino grosso nos animais suplementados com leguminosa, como já citado anteriormente. Isso porque a digestibilidade das dietas pode afetar o tempo de permanência dos alimentos no trato digestório e o desenvolvimento deste (Jenkins, 1993). 
Carcaça e componentes...

Tabela 1. Características da carcaça de cordeiros lactentes mantidos em pasto de azevém e suplementados com concentrado ou leguminosa

\begin{tabular}{cccccc}
\hline Variáveis & Azevém & $\begin{array}{c}\text { Azevém }+ \\
\text { leguminosa }\end{array}$ & $\begin{array}{c}\text { Azevém }+ \\
\text { concentrado }\end{array}$ & CV & P \\
\hline Peso de fazenda (kg) & 32,09 & 32,22 & 32,66 & 3,30 & 0,52 \\
Perdas no jejum (\%) & 4,88 & 6,12 & 5,23 & 34,90 & 0,40 \\
Peso de abate (kg) & 30,53 & 30,24 & 30,94 & 3,42 & 0,34 \\
Peso de corpo vazio (kg) & 25,96 & 27,00 & 26,81 & 5,64 & 0,32 \\
Conteúdo TGBU (kg) & $4,60 \mathrm{a}$ & $3,25 \mathrm{~b}$ & $4,13 \mathrm{ab}$ & 19,63 & 0,005 \\
Conteúdo TGBU (\%) & $15,09 \mathrm{a}$ & $10,80 \mathrm{~b}$ & $13,38 \mathrm{ab}$ & 21,02 & 0,01 \\
PCQ (kg) & 15,11 & 15,60 & 15,52 & 8,76 & 0,73 \\
PCF (kg) & 14,51 & 15,12 & 14,90 & 8,93 & 0,62 \\
RCQ (\%) & 49,43 & 51,53 & 50,13 & 6,65 & 0,43 \\
RCF (\%) & 47,48 & 49,94 & 48,40 & 6,84 & 0,32 \\
Conformação (1-5) & 2,94 & 3,28 & 3,00 & 14,81 & 0,27 \\
Engorduramento (1-5) & 3,12 & 3,06 & 3,06 & 8,83 & 0,79 \\
EG (mm) & 1,07 & 1,22 & 1,17 & 36,90 & 0,75 \\
Textura (1-5) & 4,75 & 4,83 & 4,72 & 6,99 & 0,54 \\
Marmoreio (1-5) & 2,31 & 2,14 & 2,28 & 22,75 & 0,82 \\
QR (\%) & 3,93 & 3,10 & 3,46 & 41,96 & 0,19 \\
AOL (cm $\left.{ }^{2}\right)$ & 14,11 & 14,52 & 14,41 & 13,71 & 0,91 \\
CCar (kg/cm) & 0,27 & 0,28 & 0,28 & 8,47 & 0,51 \\
\hline
\end{tabular}

TGBU: trato gastrintestinal+bile+urina; PCQ: peso de carcaça quente, PCF: peso de carcaça fria, RCQ: rendimento de carcaça quente, RCF: rendimento de carcaça fria, EG: espessura de gordura de cobertura, QR: quebra ao resfriamento, AOL: área de olho-de-lombo, CCar: compacidade da carcaça, CV: coeficiente de variação, P: probabilidade de erro tipo I.

Tabela 2. Proporções (\% do peso de corpo vazio) dos componentes corporais de cordeiros lactentes mantidos em pasto de azevém e suplementados com concentrado ou leguminosa

\begin{tabular}{cccccc}
\hline Variáveis & Azevém & $\begin{array}{c}\text { Azevém } \\
\text { leguminosa }\end{array}$ & $\begin{array}{c}\text { Azevém }+ \\
\text { concentrado }\end{array}$ & CV & P \\
\hline Cabeça & 4,07 & 3,87 & 3,79 & 8,05 & 0,20 \\
Língua & 0,34 & 0,34 & 0,29 & 15,02 & 0,12 \\
Pulmão+traqueia & 1,66 & 1,60 & 1,72 & 9,53 & 0,28 \\
Diafragma & 0,46 & 0,47 & 0,50 & 4,55 & 0,67 \\
Timo & 0,57 & 0,63 & 0,54 & 8,06 & 0,21 \\
Esôfago & $0,15 \mathrm{a}$ & $0,14 \mathrm{ab}$ & $0,12 \mathrm{~b}$ & 15,83 & 0,008 \\
Rúmen & 1,86 & 1,82 & 1,63 & 12,18 & 0,48 \\
Retículo & 0,34 & 0,28 & 0,31 & 20,32 & 0,21 \\
Omaso & 0,19 & 0,18 & 0,17 & 32,90 & 0,80 \\
Abomaso & 0,65 & 0,61 & 0,66 & 18,04 & 0,65 \\
Intestino delgado & 3,34 & 3,34 & 3,76 & 17,62 & 0,28 \\
Intestino grosso & $1,21 \mathrm{ab}$ & $1,09 \mathrm{~b}$ & $1,35 \mathrm{a}$ & 15,08 & 0,03 \\
Fígado & $1,88 \mathrm{~b}$ & $1,99 \mathrm{ab}$ & $2,05 \mathrm{a}$ & 9,01 & 0,03 \\
Vesícula biliar & 0,02 & 0,02 & 0,02 & 5,60 & 0,21 \\
Pâncreas & 0,16 & 0,16 & 0,17 & 0,50 & 0,70 \\
Baço & 0,23 & 0,21 & 0,20 & 13,83 & 0,16 \\
Coração & 0,55 & 0,58 & 0,54 & 9,43 & 0,26 \\
Rins & 0,35 & 0,37 & 0,36 & 10,56 & 0,45 \\
Bexiga & 0,09 & 0,10 & 0,10 & 26,74 & 0,71 \\
Gordura perirrenal & 0,34 & 0,26 & 0,34 & 23,23 & 0,53 \\
Gordura coração & 0,21 & 0,17 & 0,18 & 33,26 & 0,35 \\
Gordura interna & 1,58 & 1,48 & 1,53 & 23,29 & 0,85 \\
Aparelho reprodutor & 0,46 & 0,45 & 0,41 & 11,10 & 0,69 \\
Patas & 2,86 & 2,85 & 2,87 & 6,60 & 0,98 \\
Pele & 12,44 & 11,90 & 12,25 & 30,12 & 0,95 \\
Sangue & 5,72 & 5,90 & 5,56 & 9,96 & 0,47 \\
\hline cole & & &
\end{tabular}

CV: coeficiente de variação, P: probabilidade de erro tipo I. 
Já no caso dos cordeiros suplementados com concentrado, a maior presença de amido e a proteína do concentrado na dieta, que são mais lentamente e menos extensivamente degradados no rúmen, provavelmente, fizeram com que maior quantidade dessas frações alcançasse o intestino delgado e o grosso nessa dieta (Kozloski et al., 2006).

Além disso, segundo Furlan et al. (2006), a presença de grande quantidade de nutrientes provenientes de dietas balanceadas promove maior desenvolvimento dos intestinos, pois os nutrientes que escapam da fermentação ruminal induzem o processo mitótico das vilosidades intestinais, bem como o aumento da disponibilidade de substratos no intestino aumenta a fermentação e o crescimento bacteriano nesses compartimentos, o que eleva as perdas fecais metabólicas e diminui a digestibilidade aparente (Van Soest, 1994). Isso se mostra contrário ao que provavelmente ocorreu com os animais que se alimentaram de leguminosa, uma vez que a maior parte da proteína nessas forrageiras é extensivamente degradada no rúmen (Julier et al., 2003), bem como o são os carboidratos.

A proporção de esôfago sofreu influência dos sistemas de alimentação $(\mathrm{P}<0,05)$ (Tab. 2). Houve correlação negativa $(\mathrm{P}=0,03)$ entre proporção de esôfago e de intestino grosso. Os animais que consumiram concentrado apresentaram a menor proporção de esôfago e a maior de intestino grosso, resultados esses relacionados a fatores de menor retenção ruminal da dieta, já citados anteriormente.

Em dietas em que há menor taxa de passagem, relacionada aos teores de fibra, como no caso dos animais não suplementados e mantidos no pasto de azevém, os alimentos ingeridos são mais tempo retidos no rúmen, e consequentemente os animais ruminam mais. Para Van Soest (1994), o tempo gasto na ruminação é proporcional ao teor de parede celular dos alimentos. Assim, supostamente, essa maior ruminação levou ao maior uso do esôfago, o que aumentou sua proporção.

Houve efeito do sistema de alimentação sobre a proporção de fígado dos animais $(\mathrm{P}<0,05)$ (Tab. 2), e isso pode ser atribuído às características das dietas. O aumento do consumo de carboidratos não estruturais pode levar à elevação do tamanho do fígado, uma vez que o principal local de metabolismo do propionato produzido na digestão fermentativa desses carboidratos é esse órgão (Brochier e Carvalho, 2008).

Dessa maneira, em virtude da maior quantidade de carboidratos não estruturais presentes na dieta dos animais alimentados com suplemento concentrado, estes apresentaram maiores proporções de fígado. Além disso, em razão da maior participação de carboidratos estruturais na dieta dos cordeiros lactentes que não recebiam suplementação, encontrou-se menor proporção de fígado.

O fígado apresenta elevada taxa metabólica, sendo essa atividade intensificada quando há aumento do nível de energia na dieta. Consequentemente, esse órgão apresenta maior desenvolvimento para conseguir atender à demanda do metabolismo dos nutrientes, portanto o aumento de energia da dieta estimula o desenvolvimento do fígado (Camilo et al., 2012). Justifica-se, assim, a maior proporção desse órgão quando a suplementação concentrada esteve presente e a menor quando não houve suplementação dos cordeiros.

Não foram encontradas diferenças $(\mathrm{P}>0,05)$ nas medidas da carcaça (Tab. 3), nos pesos e rendimentos de cortes (Tab. 4) e na composição tecidual da paleta (Tab. 5). $\mathrm{O}$ peso preestabelecido, bem como a similaridade nas carcaças dos animais (Tab. 1), contribuiu para esses resultados. Ribeiro et al. (2013) não encontraram diferenças nas carcaças de cordeiros lactentes suplementados com trevo-branco quando comparados com os mantidos em azevém. Os mesmos autores concluíram que sistemas de suplementação (com concentrado ou leguminosa) não interferem nos aspectos morfológicos dos cordeiros, de suas carcaças, de seus cortes e demais componentes, resultando em carcaças homogêneas e de padrão adequado para o mercado consumidor nacional. Esses resultados são semelhantes ao desta pesquisa, já que as carcaças produzidas foram de alta qualidade (bons pesos, rendimentos e cobertura de gordura) e com características semelhantes (Tab. 1).

$\mathrm{Na}$ carcaça, aumentos no estado de engorduramento e de gordura de cobertura foram encontrados em cordeiros que pastejaram trevo quando comparados aos mantidos em azevém 
(Cramer et al., 1967). Esse fato pode ter ocorrido devido à maior qualidade nutricional do trevobranco, porém, em razão de os cordeiros ainda serem lactentes e estarem em pastejo de azevém, a presença do leite da ovelha e a oferta de pastagem de qualidade na dieta foram fatores importantes para a padronização da quantidade de gordura nas carcaças.

Tabela 3. Medidas da carcaça $(\mathrm{cm})$ de cordeiros lactentes mantidos em pasto de azevém e suplementados com concentrado ou leguminosa

\begin{tabular}{cccccc} 
Variáveis & Azevém & $\begin{array}{c}\text { Azevém }+ \\
\text { leguminosa }\end{array}$ & $\begin{array}{c}\text { Azevém }+ \\
\text { concentrado }\end{array}$ & CV & P \\
\hline Comprimento de carcaça & 54,12 & 53,67 & 54,28 & 2,78 & 0,67 \\
Comprimento de perna & 36,37 & 35,78 & 35,67 & 3,04 & 0,38 \\
Profundidade de peito & 24,25 & 24,94 & 24,89 & 3,49 & 0,21 \\
Largura de perna & 10,00 & 10,22 & 10,44 & 7,28 & 0,48 \\
Profundidade de perna & 13,61 & 14,31 & 14,00 & 5,05 & 0,15 \\
\hline
\end{tabular}

$\mathrm{CV}$ : coeficiente de variação, P: probabilidade de erro tipo I.

Tabela 4. Cortes comerciais da carcaça de cordeiros lactentes mantidos em pasto de azevém e suplementados com concentrado ou leguminosa

\begin{tabular}{cccccc}
\hline Variáveis & Azevém & $\begin{array}{c}\text { Azevém }+ \\
\text { leguminosa }\end{array}$ & $\begin{array}{c}\text { Azevém }+ \\
\text { concentrado }\end{array}$ & $\mathrm{CV}$ & $\mathrm{P}$ \\
\hline Pescoço $(\mathrm{kg})$ & 0,359 & 0,383 & 0,337 & 12,44 & 0,11 \\
Paleta $(\mathrm{kg})$ & 1,525 & 1,579 & 1,595 & 9,08 & 0,58 \\
Costela $(\mathrm{kg})$ & 2,709 & 2,884 & 2,800 & 11,00 & 0,51 \\
Pernil $(\mathrm{kg})$ & 2,557 & 2,601 & 2,629 & 8,23 & 0,79 \\
Pescoço (\%) & 5,04 & 5,19 & 4,52 & 12,20 & 0,07 \\
Paleta (\%) & 21,34 & 21,24 & 21,42 & 3,06 & 0,85 \\
Costela (\%) & 37,84 & 38,72 & 37,58 & 4,18 & 0,30 \\
Pernil (\%) & 35,59 & 35,01 & 35,38 & 3,81 & 0,50 \\
L. dorsi $(\mathrm{kg})$ & 0,914 & 0,931 & 0,952 & 10,43 & 0,73 \\
\hline
\end{tabular}

CV: coeficiente de variação, P: probabilidade de erro tipo I.

Tabela 5. Composição tecidual da paleta de cordeiros lactentes mantidos em pasto de azevém e suplementados com concentrado ou leguminosa

\begin{tabular}{cccccc}
\hline Variáveis & Azevém & $\begin{array}{c}\text { Azevém }+ \\
\text { leguminosa }\end{array}$ & $\begin{array}{c}\text { Azevém }+ \\
\text { concentrado }\end{array}$ & $\mathrm{CV}$ & $\mathrm{P}$ \\
\hline Paleta descongelada (kg) & 1,518 & 1,577 & 1,591 & 9,10 & 0,54 \\
Osso (kg) & 0,271 & 0,282 & 0,278 & 6,59 & 0,49 \\
Músculo (kg) & 0,870 & 0,898 & 0,921 & 8,68 & 0,42 \\
Gordura (kg) & 0,230 & 0,250 & 0,235 & 26,67 & 0,79 \\
Outros (kg) & 0,099 & 0,091 & 0,097 & 15,52 & 0,50 \\
Osso (\%) & 17,94 & 17,94 & 17,57 & 7,57 & 0,80 \\
Músculo (\%) & 57,34 & 57,02 & 57,95 & 3,90 & 0,68 \\
Gordura (\%) & 15,01 & 15,71 & 14,58 & 20,06 & 0,73 \\
Outros (\%) & 6,55 & 5,79 & 6,11 & 15,72 & 0,29 \\
Músculo:godura & 3,78 & 3,59 & 3,91 & 24,30 & 0,56 \\
Músculo:osso & 3,22 & 3,19 & 3,31 & 7,80 & 0,54 \\
\hline
\end{tabular}

CV: coeficiente de variação, P: probabilidade de erro tipo I.

\section{CONCLUSÕES}

Cordeiros lactentes mantidos em pastejo de azevém produzem carcaças de qualidade semelhante, se suplementados ou não. $\mathrm{O}$ conteúdo do trato gastrintestinal juntamente com bile e urina foi maior nos cordeiros que não receberam suplementação e menor nos suplementados com leguminosa. Os cordeiros lactentes mantidos em pasto de azevém tiveram 
as maiores proporções de esôfago e as menores proporções de fígado. Já os cordeiros suplementados com concentrado tiveram as menores proporções de esôfago e as maiores proporções de fígado. A proporção de intestino grosso foi superior nos cordeiros suplementados com concentrado e inferior nos suplementados com leguminosa.

\section{REFERÊNCIAS}

BARROS, C.S.; MONTEIRO, A.L.G.; POLI, C.H.E.C. et al. Rentabilidade da produção de ovinos de corte em pastagem e em confinamento. Rev. Bras. Zootec., v.38, p.2270-2279, 2009.

BROCHIER, M.A.; CARVALHO, S. Peso e rendimento dos componentes do peso vivo de cordeiros terminados em confinamento com dietas contendo proporções crescentes de resíduo úmido de cervejaria. Arq. Bras. Med. Vet. Zootec., v.60, p.1213-1218, 2008.

CAMILO, D.A.; PEREIRA, E.S.; PIMENTEL, P.G. et al. Peso e rendimento dos componentes não-carcaça de ovinos Morada Nova alimentados com diferentes níveis de energia metabolizável. Semin. Cienc. Agrar., v.33, p.2429-2440, 2012.

COLOMER-ROCHER, F.; MORAND-FEHR, P.; KIRTON, A.H. et al. Métodos normalizados para el estudio de los caracteres cuantitativos y cualitativos de las canales caprinas y ovinas. Madrid: INIA, 1988. 41p.

COSTA, J.C.C.; OSÓRIO, J.C.S.; OSÓRIO, M.T.M. et al. Produção de carne de ovinos Corriedale terminados em três sistemas de alimentação. Rev. Bras. Agrocienc., v.15, p.83$87,2009$.

CRAMER, D.A.; BARTON, R.A.; SHORLAND, F.B.; CZOCHANSKA, Z.A comparison of the effects of white clover (Trifolium repens) and of perennial ryegrass (Lolium perenne) on fat composition and flavour of lamb. J. Agric. Sci., p.367-373, 1967.

FURLAN, R.L.; MACARI, M.; FARIA FILHO, D.E. Anatomia e fisiologia do trato gastrintestinal. In: BERCHIELLI, T.T.; PIRES, A.V.; OLIVEIRA, S.G. (Eds.). Nutrição de ruminantes. Jaboticabal: Funep, 2006. p.1-23.
HASHIMOTO, J. H.; OSÓRIO, J.C.S.; OSÓRIO, M.T.M. et al. Avaliação in vivo e da carcaça de cordeiros Corriedale de diferentes sexos. Rev. FZVA, v.16, p.196-204, 2009.

JENKINS, T.C. Lipid metabolism in the rumen. J. Dairy Sci., v.76, p.3851-3863, 1993.

JULIER, B.; GUINES, F.; EMILE, J.C.; HUYGHE, C. Variation in protein degradability in dried forage legumes. Anim. Res., v.52, p.401412, 2003.

KOZLOSKI, G.V.; TREVISAN, L.M.; BONNECARRÈRE, L.M. et al. Níveis de fibra em detergente neutro na dieta de cordeiros: consumo, digestibilidade e fermentação ruminal. Arq. Bras. Med. Vet. Zootec., v.58, p.893-900, 2006.

MOTT, G.O.; LUCAS, H.L. The design, conduct, and interpretation of grazing trials in cultivated and improved pastures. In: INTERNATIONAL CONGRESS, 6., 1952, Pennsylvania. Proceedings... Pennsylvania: State College Press, 1952. p.1380-1385.

OSÓRIO, J.C.S.; OSÓRIO, M.T.M.; JARDIM, P.O. et al. Métodos para avaliação da produção de carne ovina: "in vivo" na carcaça e na carne. Pelotas: UFPEL, 1998. 107p.

PIAZZETTA, H.V.L.; MONTEIRO, A.L.G.; RIBEIRO, T.M.D. et al. Comportamento ingestivo de cordeiros em terminação a pasto. Acta Sci. Anim. Sci., v.31, p.222-234, 2009.

RIBEIRO, T.M.D.; COSTA, C.; MONTEIRO, A.L.G. et al. Características das carcaças de cordeiros lactentes terminados em creep feeding e creep grazing. Vet. Zootec., v.20, p.9-17, 2013.

SAS user's guide, versão 9.2. Cary: SAS, 2008. 1680p.

SOUZA, S.; LEAL, A.; BARIONI, C. et al. Utilização de medidas biométricas para estimar peso vivo em ovinos. Arch. Latinoam. Prod. Anim., v.17, p.61-66, 2009.

VAN SOEST, P.J. Nutritional ecology of the ruminant. 2.ed. New York: Cornell University Press, 1994. 476p. 